Article

\title{
Heuristic Thinking and Credibility of Organic Advertising Claims: The Role of Knowledge and Motivations
}

\author{
Ana Lanero * ${ }^{\mathbb{D}}$, José-Luis Vázquez and César Sahelices-Pinto \\ Department of Business Economics and Management, Faculty of Economics and Business Sciences, University of \\ León, 24071 León, Spain; jose-luis.vazquez@unileon.es (J.-L.V.); cesar.sahelices@unileon.es (C.S.-P.) \\ * Correspondence: ana.lanero@unileon.es; Tel.: +34-987-293296
}

Received: 25 September 2020; Accepted: 20 October 2020; Published: 22 October 2020

check for updates

\begin{abstract}
Consumers are often overexposed to sustainability symbols and claims on food product packages and find it difficult to accurately judge their meaning when making purchase decisions. Based on the heuristic-systematic model (HSM), this paper aims to identify cognitive mechanisms to reduce the heuristic credibility of organic advertising claims and to increase the motivation for searching for more reliable information when making product judgements. Particularly, we hypothesize that knowledge and defense and accuracy motivations affect organic claim credibility, which in turn is related to organic product judgement. Data collected from an experimental between-subject study with a sample of 412 Spanish undergraduates was analyzed using partial least squares. The results indicated that claim credibility was directly related to the attribution of organic properties to products, and was affected by defense motivation especially when appropriate knowledge was not available. Improving consumers' knowledge reduced organic claim credibility and triggered a positive effect of accuracy motivation on credibility. The findings stress the importance of improving the regulation of ambitious advertising claims and developing specific educational campaigns to empower consumers and prevent biased purchase decisions of organic products.
\end{abstract}

Keywords: heuristic-systematic model (HSM); eco-labelling; organic claims; claim credibility; organic product judgement; knowledge; defense motivation; accuracy motivation

\section{Introduction}

Once conscious of the growing eco-awareness of many consumers, more and more brands in the food industry are using green marketing campaigns to engage their customers as well as to trying to involve them in environmentally-friendly shopping behaviors. In this sense, the use of declarations and organic labels in product packaging has become a habitual advertising tool to communicate their environmental superiority [1-3]. However, the meaning and legitimacy of such claims seem quite variable, so that official eco-labels which are certified by independent third bodies coexist with many other advertising claims and self-statements by the companies themselves about the sustainability of their products $[4,5]$. This phenomenon has led to the development of specific legislation on certification and labelling, aimed at protecting consumers and guaranteeing fair competition. For example, current European rules establish the use of the EU organic logo in the labelling of organic agricultural products which have succeeded the control assessment carried out by a competent body, and authorizes the use of the term 'organic' (as well as its corresponding translation into other EU languages) as an advertising claim exclusively linked to such products [6].

Nevertheless, empirical evidence suggests that advertising claims appear more effective than official eco-labels for individuals to identify a product as organic, as allowing a faster processing 
of information and requiring less cognitive understanding effort [4]. Thus, many different studies conclude that in busy and distracting environments, where it is not possible to reflect thoughtfully on information, consumers use heuristics or simple cues to evaluate the attributes of the products with minimal efforts [7-9]. Hence, the previous literature has shown that identifying products as 'organic' or 'eco-friendly' strongly affects automatic perceptions of their environmental attributes and other purchase-relevant judgments [3,10-12]. Differently, the interpretation of official labels and badges requires prior knowledge about the meaning of the symbols and codes used which are not so usual to consumers [13-16]. A number of companies take advantage of consumers' superficial processing of advertising symbols to use confusing verbal claims on packaging $[5,17,18]$. So, there are unregulated terms such as 'natural' or 'artisan' that can lead the consumer to think that a product has concrete organic properties and mistakenly considering them as implicit $[4,19,20]$. This way, the credibility level given to these verbal claims avoids the search of additional information based on official evidence, often leading to biased purchase decisions [21,22].

In this context, this paper aims to identify the cognitive mechanisms involved in reducing the heuristic credibility of advertising claims related to ecological attributes of products and to increase the motivation for searching for more reliable official indications when making judgements about organic products. At this purpose, the heuristic-systematic model (HSM) is taken as a theoretical frame of reference, which posits two fundamental modes of thinking in decision making, namely, heuristic processing and systematic processing [23-26]. The HSM has been applied by different authors to explain the cognitive processing of eco-labels and ethical claims, concluding that consumers tend to use heuristic cues and cognitive biases appear when individuals make judgements about their meaning $[3,4,27]$. This paper advances this line of work by identifying mechanisms to modify the superficial processing of advertising symbols related to sustainability and to elicit purchase decisions based on quick, but accurate and informed judgements on the organic attributes of products.

To be precise, we suggest providing the consumer with truthful basic information regarding certification and eco-labelling in order to increase his/her skepticism about the most visible ecological advertising claims and to generate cognitive capacity enough to motivate more critical and effective thinking as the basis of potential purchase decisions. Obtained results are useful for public authorities devoted to the design of consumer protection policies and for entities committed to the fight against greenwashing by empowering consumers and preventing biased purchase decisions. Likewise, the conclusions of the research can be used by those responsible for marketing departments in companies commercializing organic products when designing promotional campaigns through which consumers could quickly and accurately assess the 'green' benefits of the products provided.

This paper is organized as follows. The next sections describe the HSM and propose certain hypotheses to explain organic product judgement based on perceived claim credibility, knowledge, and defense and accuracy motivations. Immediately thereafter, we present an empirical study to test the model with a partial least squares (PLS) technique. Last, conclusions and implications are discussed.

\section{Literature Review}

\subsection{Heuristic-Systematic Model (HSM)}

The HSM proposes two fundamental information-processing modes to reach a judgment [23-26]. Systematic processing involves a comprehensive, analytic orientation in which the perceivers access, scrutinize, and integrate all relevant pieces of information and elaborate them to reach their judgements. In contrast, the heuristic processing mode involves the use of learned knowledge structures in the form of simple decision cues to reach quick judgments. The main advantage of heuristic thinking is allowing less demanding and more efficient decisions, as it is based on previously available, accessible, and applicable learning [28-30]. However, its main risk is that it often ignores some of the relevant information and this can lead to biased judgements [9,31,32]. 
In this paper, we will consider the object of judgment to be the meaning of 'organic product' attributed to an advertising claim. As such advertising claims are not official in themselves, consumers need to be able to search for and correctly understand other independent labels and certifications in the product (e.g., the EU organic logo) to make an unequivocal accurate judgement [13], thus carrying out a systematic processing. Nevertheless, the empirical evidence on cognitive processing of eco-labels and ethical claims shows that consumers tend to apply a superficial processing which is poorly supported by good evidence when evaluating product attributes. Table 1 summarizes some findings of this line of research.

Table 1. Previous findings on cognitive processing of eco-labels and claims.

\begin{tabular}{cc}
\hline Authors & Main Findings \\
\hline Hoek et al. [4] & $\begin{array}{r}\text { Consumers are influenced by ambiguous and non-scientific claims and respond strongly } \\
\text { to heuristic cues, even though they believe themselves skeptical. }\end{array}$ \\
\hline Bradu et al. [27] & $\begin{array}{c}\text { Ethical labels influence consumer decision-making activating a holistic affective } \\
\text { evaluation of the product, inducing heuristic rather than elaborate cognitive processing. }\end{array}$ \\
\hline Schleenbecker and Hamm [15] & $\begin{array}{c}\text { Even when sustainability information on product packages plays an important role and } \\
\text { is retrieved rather extensively, consumers tend to apply search strategies that reduce the } \\
\text { information processing effort. }\end{array}$ \\
\hline Maniatis [5] & $\begin{array}{c}\text { Consumers tend to positively interpret products as organic when visual package } \\
\text { appearance and verbal sustainability claims are congruent, independently of their } \\
\text { environmental concern. }\end{array}$ \\
\hline Hayat et al. [33] & $\begin{array}{c}\text { Consumers usually lack sufficient understanding of the traces of sources of green } \\
\text { benefits, and tend to mix their green knowledge and attitudes with trust in certifications. }\end{array}$ \\
\hline $\begin{array}{c}\text { Signals of corporate social responsibility (CSR) toward the environment are positively } \\
\text { related to consumer trust, which further leads to impulsive buying without earlier } \\
\text { planning and adequate information about the product. }\end{array}$ \\
\hline
\end{tabular}

Based on these previous results, this paper raises the convenience of identifying mechanisms to encourage more systematic thinking in consumers, leading them to critically and correctly evaluate the advertising symbols appealing to the organic attributes of products, as a basis to build an effective heuristic thinking. In this regard, it is known that individuals usually take advantage of non-biased heuristic processing after carefully examining the arguments of the systematic processing [28]. Accordingly, expert green consumers have been found to use a deliberate decision-making mode in their initial choices of green products, searching for relevant information and devoting enough time to reach a precise judgement, until they are able to identify eco-labels easily, and just use them as heuristics that allow them to make satisfactory decisions with little effort [3,34,35].

According to the HSM, getting consumers involved in applying the systematic processing mode when assessing advertising claims about 'green' or 'organic' products requires that they possess adequate levels of both cognitive capacity and motivation [26]. On the one hand, limited knowledge in a given area, time constraints, or the presence of numerous processing tasks reduce systematic processing and increase reliance in heuristics [26,36,37]. On the other hand, motivation for accurate processing is determined by the gap between the level of actual confidence in one's judgment and the level of desired confidence, or sufficiency threshold [26,28,38,39]. Following these postulates, we hypothesize that providing basic and truthful information on certification and eco-labelling represents a core tool to increase the cognitive capacity and accuracy motivation of consumers in their judgements about organic products and, therefore, the possibilities of using a more systematic thinking. The cognitive mechanism through which we understand the change between heuristic and systematic modes occurs is the reduction of the credibility of the advertising symbol, which implies the need to seek additional information to make an accurate judgement. These arguments are developed in the next sections and the research hypotheses are also presented. 


\subsection{Knowledge, Claim Credibility, and Organic Product Judgement}

According to the HSM, if consumers have cognitive capacity enough, they will carry out systematic processing of the symbols associated to the organic properties of the products [26]. In this sense, the purchase of food products is usually characterized by the presence of frequent time constraints and simultaneous processing tasks, due to the fact that decisions to purchase products that are acquired jointly are taken at a same time. As these tend to be low-implication products, the decision maker does not spend too much time evaluating them individually $[4,7,8]$. Under such circumstances, one of the concrete functions of eco-labels and ecological badges is to act as credibility cues simplifying consumer decision-making by facilitating the identification of environmentally superior products $[2,15,40-42]$.

In the context of this research, credibility can be defined as consumers' overall perception regarding the trustworthiness of the claim, rather than its meaning [23]. Different studies confirm that credibility and trust in green labels and claims are strongly related to their use in purchase decisions $[13,14,16,43-45]$, even when consumers lack a thorough knowledge of the verification process of the various environmental labels $[5,46]$. Therefore, the credibility of the advertising claim can be expected to act as a heuristic cue for the consumer when making his/her quick judgements about supposedly organic products, regardless of having adequate knowledge about its meaning. Thus, we posit the first hypothesis as follows:

Hypothesis 1 (H1). Claim credibility has a positive effect on organic product judgment.

Going further according to the HSM postulates, the vulnerability of the consumer to make a biased heuristic judgement or his/her ability to detect the need to complete the information provided by the commercial claim with other kind of official indications through more systematic reasoning will depend on the availability of prior knowledge [26]. In this sense, a recent choice experiment allowed Stanton and Cook [3] to observe that the more consumers increase their knowledge on organic food, the more they are prepared to seek specific details about each product choice compared to consumers with low levels of knowledge, who are more likely to use peripheral heuristic cues such as brand and price. Many other studies support the idea that label understanding is a prerequisite for label awareness and correct use in decision-making [1,22,41,45,47].

Consistently, previous contributions in literature suggest that more informed and environmentally concerned consumers tend to be more skeptical about the credibility of green claims and thus less likely to process them heuristically and more inclined to scrutinize labels [3,10,48]. Based on this reasoning, we hypothesize that consumers with a higher level of knowledge about certification and eco-labelling will attribute less credibility to the commercial claim as knowing its unofficial nature when compared to other certifications. On the contrary, consumers with a lower level of knowledge will use heuristic thinking based on the attribution of a greater credibility to the claim, issuing positive judgements on its supposed organic nature to a greater extent. Thus, the second hypothesis is laid as:

Hypothesis 2 (H2). Knowledge has a negative effect on claim credibility.

\subsection{Accuracy and Defense Motivations}

According to the HSM, the second factor necessary for systematic processing to occur is accuracy motivation. Thus, the credibility of a commercial claim will lead to a heuristic judgement on its ecological significance to the extent it allows reaching adequate levels of desired confidence $[5,26,28]$. This low motivation to systematically process claims is expected to occur in the absence of appropriate knowledge about the scope and legitimacy of different ecological symbols, as the consumer does not have the cognitive capacity to successfully evaluate relevant product attributes [3].

Related to the above, previous literature supports the idea that consumers are less willing to critically analyze the organic character of products and to trust in the more visual commercial information when this is congruent with pro-environmental self-definitional attitudes and 
beliefs $[12,45,49,50]$. Particularly, green labels have been said to create a cognitive match between the labelled product and consumers' motives, so that consumers with high ecological motivation have strong preferences for green-labelled products, even when presented product information contradicts the label's image $[20,51]$. According to the HSM, this type of defense motivation is associated to the use of heuristic thinking when it allows preserving enduring values and beliefs that are critical to the individual $[26,29,39]$. In other words, despite the fact consumers do not have knowledge enough to correctly interpret an organic distinctive, they can give it credibility to the extent that it is consistent with their knowledge and attitudes [5]. Any factor that increases the gap between actual and desired confidence in one's judgment should increase systematic processing $[26,28,38]$. Following the line of argument from the previous section, generating knowledge in consumers can increase the gap between actual and desired confidence, so reducing the credibility of the commercial distinctive and the resulting judgement $[3,10,48]$. Under these circumstances, the influence of the defense motivation on the credibility of the claim is expected to reduce, since the consumer will not be able to reinforce the positive image of him/herself through a distinctive that he/she does not know is true. According to the HSM, such knowledge increase will turn into more systematic processing $[26,28,38]$ as consumers get more prepared to seek specific details [3,52]. Hence, for high-knowledge consumers, accuracy motivation will lead them to attribute less credibility and less ecological significance to the commercial claim, given the need to justify their judgements with additional more reliable information.

On this reasoning, the remaining hypotheses are laid as follows:

Hypothesis 3a (H3a). Defense motivation has a positive effect on claim credibility.

Hypothesis $\mathbf{3 b} \mathbf{( H 3 b )}$. Knowledge moderates the positive effect of defense motivation on claim credibility, so that this effect is stronger for low levels of knowledge.

Hypothesis 4a (H4a). Accuracy motivation has a negative effect on claim credibility.

Hypothesis $4 \mathbf{b}(\mathbf{H} 4 \mathbf{b})$. Knowledge moderates the negative effect of accuracy motivation on claim credibility, so that this effect is stronger for high levels of knowledge.

\section{Materials and Methods}

\subsection{Sample and Procedure}

To test the hypotheses of the model, we conducted an experimental between-subject study with a sample of undergraduate business students at the University of León, in Spain. We chose students to investigate organic claim processing because younger generations are usually considered more responsive to sustainability issues than previous generations [49,53-55]. Likewise, we used a homogenous sample of students within the same study area to ensure that they presented similar levels of prior knowledge on issues related to sustainability and eco-labelling.

A total of 477 participants were initially involved in the study, all attending regular university classes selected on a convenience basis. Sixty-five of them were discarded either for being significantly older than their peers, providing incomplete information at some stage of the experiment, or declaring never to participate in their daily life in the purchase of unprocessed fruits-this being the category of product analyzed in our study (see following sections). Therefore, the final sample was made up of 412 students 18 to 26 years old $(M=20.42$ years; $S D=2.08$ years), 223 being females $(54.1 \%)$ and 189 males $(45.9 \%)$. Concerning shopping habits, $54.8 \%$ of the individuals in the final sample declared to purchase unprocessed fruit at least once a week, $25.3 \%$ two to three times a month, 5.7\% once a month, and $14.2 \%$ less than once a month. The 412 participants in the study were distributed in two experimental conditions with a similar composition: High-knowledge group $(n=202)$ and low-knowledge group $(n=210)$. 
The research procedure used in the high-knowledge group was developed in two steps. In the first step, participants were asked to answer a questionnaire about their knowledge related to certification and eco-labelling and their accuracy and defense motivations when considering eco-criteria in their purchase decisions. This was followed by a 15-min training on basic concepts associated with the organic properties of products, official certification procedures and categories of eco-labels, and European regulations regarding the use of symbols and terms as advertising claims in the marketing of organic products. Then, in the second step of the study, which was carried out two weeks after the first one, the participants' knowledge about certification and eco-labelling was re-evaluated. Next, they were presented the image of a commercial claim used by a well-known Spanish brand of organic bananas to advertise their products on the packaging, consisting of the brand's logo and the term 'organic'. Respondents were asked to assess the credibility of the claim and to make a judgement about the organic product nature associated to it.

Those participants assigned to the low-knowledge group did not receive any training and the procedure was developed in a single session where they answered a questionnaire about knowledge, motivations, and credibility and judgement of organic products associated with the same image of the commercial claim presented in the other group.

\subsection{Product Category and Organic Claim}

Bananas were chosen as the product category for the study purposes as being one of the fresh fruits to which Spanish households spend a greater percentage of their budget for the purchase of food and beverage products [56], in addition to being the fruit most consumed by young people between 18 and 30 years old [57]. Around 70\% of the bananas consumed in Spain are produced in the country, the remaining 30\% corresponding to bananas of different origins, mainly Belize, Costa Rica, Cameroon, Panama, Colombia, Mexico, and Ivory Coast [58]. The total Spanish banana production is concentrated in the Canary Islands and is marketed through the Association of Organizations of Banana Producers of the Canary Islands (ASPROCAN) through a single brand bringing together all producers. The banana from the Canary Islands is also the only product of this type with the European recognition of protected geographical indication (PGI), which guarantees its uniqueness and origin as well as positions it as an easily differentiable product against foreign competitors [59].

Currently, less than $5 \%$ of the banana growing area in the Canary Islands is dedicated to the production of organic bananas [60]. The sale of organic bananas is done in bulk exclusively in eco-stores and packaged in the rest of the markets, having to comply with the requirements established by the European regulations on labelling [6]. In this regard, the competent authority for the control and certification of food products of agricultural origin or handled in their final manufacturing phase in the Autonomous Community of the Canary Islands is the Canarian Institute of Agrofood Quality (ICCA), which establishes the obligation to identify in the labelling or advertising of organic bananas the terms 'ecological', 'biological', and/or 'organic' or their diminutives, together with the numerical code of the control authority (ES-ECO-014-IC), the EU logo, the ICCA logo, and the indication of the origin of raw materials.

According to the research procedure described in the previous section, the commercial claim presented to the participants to assess the perceived credibility and the resulting organic nature judgement consisted of the recognizable logo of the general banana brand from the Canary Islands and the term 'organic'. This selection made it possible to control the effect of the brand's notoriety and ensure that participants share a similar assessment regarding price and quality attributes, in addition to providing incomplete information to accurately judge the organic nature of the product.

\subsection{Measures}

A questionnaire was developed for data collection in the different steps of the research. To ensure content validity of the scales, a deductive approach was followed that was based on a thorough review of the specialized literature and other similar instruments [61]. Additionally, the selection of the indicators 
was based on the judgment of three experts and the results of a pre-test conducted with a small group of undergraduate students who were consulted about the difficulty and their understanding of the content. To minimize social desirability and acquiescence biases, respondents were requested to respond to the survey anonymously and as honestly as possible [62]. In both subsamples, the surveys were collectively administered according to a pre-determined schedule in teaching classrooms, which were selected for reasons of convenience. Data were collected anonymously using a paper and pencil mixed survey instrument in the presence of a qualified researcher. The Appendix A illustrates the measurement scales used in the study.

Knowledge. Consistent with previous studies using subjective measures of label knowledge and understanding $[3,45,47]$, participants were asked to report their level of knowledge on six contents related to organic certification and labelling on a five-point scale $(1=$ no knowledge; $5=$ high knowledge). The scale obtained a Cronbach's alpha reliability of 0.77 in the case of those participants assigned to the high-knowledge condition during the pre-training step, which increased to 0.84 during the post-training phase, the same value for participants assigned to the low-knowledge condition. Two Student's $t$-tests were performed to verify the effect of the training on certification and eco-labelling given to individuals in one of the subsamples and to justify the distribution of the participants in the high-knowledge and low-knowledge groups. On the one hand, we compared the level of knowledge of the individuals in the high-knowledge group prior to the training action $(M=2.55 ; D T=0.65)$ and the subsequent moment two weeks later $(M=3.38 ; D T=0.72)$, obtaining statistically significant differences according to a $t$-value $=13.79(p<0.05)$. On the other hand, there were differences between the values obtained for the individuals in the high-knowledge group once the formation was received $(M=3.38 ; D T=0.72)$ and the participants in the low-knowledge group, who did not receive training $(M=2.92 ; D T=0.72)$, according to a $t$-value $=6.38(p<0.05)$.

Defense and accuracy motivations. Based on HSM literature $[26,29,39]$ and previous studies on green purchase motivations [49,51], participants were requested to report their level of identification with several sentences defining motivations when buying fresh fruits and vegetables, according to a five-point scale ( $1=$ not identified at all; $5=$ completely identified). The scale for defense motivations consisted of seven items related to the purchase of organic products to reinforce existing self-definitional attitudes and beliefs. The accuracy motivations scale consisted of eight items reflecting a personal need to ensure and look for signs that the products have properties linked to organic farming.

Claim credibility. According to previous studies on trust in green labels and claims [13,16,43,45], participants were asked to assess the organic claim used in the study in seven indicators of credibility (e.g., official, reliable, objective, etc.), according to a five-point scale ( $1=$ nothing at all; $5=$ completely).

Organic product judgement. The participants were presented a list of seven basic defining characteristics of an organic product in accordance with current European regulations on organic farming [6]. In each case, participants had to indicate to what extent they associated the advertising claim used in the study with a banana of the concrete characteristic, according to a five-point scale ( $1=$ nothing at all; $5=$ completely).

\subsection{Data Analysis}

The research model was examined using partial least squares (PLS) through the statistical program SmartPLS 3.0 [63]. Unlike covariance-based methods, PLS aims to maximize the variance explained by indicators and latent variables through the estimation of ordinary least squares and principal component analysis. In this context, data treatment responds to the creation of optimal linear predictive paths with minimal demands on measurement scales, residual distributions, and sample sizes [64-66]. Therefore, compared with maximum likelihood methods, the PLS approach better fits the requirements of exploratory and theory-building applications [64,67], such as in this research. For reflective measurement approaches, the PLS procedure allows for estimating the research model in two stages [68]. The first stage evaluates the strength of the measurement model (also known as the outer model) by looking at item reliabilities, internal consistency, and construct validity. The second 
stage focuses on the estimation of the fit parameters for the structural model (inner model) and reports on the fulfilment of the research hypotheses.

\section{Results}

\subsection{Assessment of the Measurement Model}

Table 2 shows the items included in the measurement model and their psychometric properties. Item reliabilities were evaluated by examining the significance of the standardized loadings $(\lambda)$ or simple correlations of indicators with their respective latent variables. All loadings were above the threshold of $0.50[67,69]$, according to a significance level of $p<0.05$, and calculated on the basis of 500 bootstrapping runs. Likewise, item communalities $\left(\lambda^{2}\right)$ exceeded the minimum requirement of 0.25 , such that the latent constructs explained between $30 \%$ and $66 \%$ of variance in their respective observed indicators.

Table 2. Measurement model assessment.

\begin{tabular}{|c|c|c|c|c|c|}
\hline $\begin{array}{l}\text { Constructs } \\
\text { and Items }\end{array}$ & Loading $(\lambda)$ & $\begin{array}{c}\text { Communality } \\
\left(\lambda^{2}\right)\end{array}$ & $\begin{array}{l}\text { Cronbach's } \\
\text { Alpha }(\alpha)\end{array}$ & $\begin{array}{c}\text { Composite } \\
\text { Reliability }\left(\rho_{c}\right)\end{array}$ & $\begin{array}{l}\text { Average Variance } \\
\text { Extracted (AVE) }\end{array}$ \\
\hline \multicolumn{3}{|c|}{ Defense Motivation } & 0.84 & 0.88 & 0.51 \\
\hline DM1 & $0.63^{* * *}$ & 0.40 & & & \\
\hline DM2 & $0.55^{* * *}$ & 0.30 & & & \\
\hline DM3 & $0.79 * * *$ & 0.62 & & & \\
\hline DM4 & $0.75^{* * *}$ & 0.56 & & & \\
\hline DM5 & $0.71^{* * *}$ & 0.50 & & & \\
\hline DM6 & $0.78^{* * *}$ & 0.61 & & & \\
\hline DM7 & $0.75^{* * *}$ & 0.56 & & & \\
\hline \multicolumn{3}{|c|}{ Accuracy Motivation } & 0.87 & 0.89 & 0.51 \\
\hline DM1 & $0.75^{* * *}$ & 0.56 & & & \\
\hline DM2 & $0.63^{* * *}$ & 0.40 & & & \\
\hline DM3 & $0.71^{* * *}$ & 0.50 & & & \\
\hline DM4 & $0.74^{* * *}$ & 0.55 & & & \\
\hline DM5 & $0.81^{* * *}$ & 0.66 & & & \\
\hline DM6 & $0.72^{* * *}$ & 0.52 & & & \\
\hline DM7 & $0.77^{* * *}$ & 0.59 & & & \\
\hline DM8 & $0.58^{* * *}$ & 0.34 & & & \\
\hline \multicolumn{3}{|c|}{ Claim Credibility } & 0.88 & 0.91 & 0.59 \\
\hline $\mathrm{CC} 1$ & $0.73^{* * *}$ & 0.53 & & & \\
\hline $\mathrm{CC} 2$ & $0.80 * * *$ & 0.64 & & & \\
\hline CC3 & $0.79^{* * *}$ & 0.62 & & & \\
\hline $\mathrm{CC} 4$ & $0.80 * * *$ & 0.64 & & & \\
\hline CC5 & $0.73^{* * *}$ & 0.53 & & & \\
\hline CC6 & $0.70 * * *$ & 0.49 & & & \\
\hline CC7 & $0.80^{* * *}$ & 0.64 & & & \\
\hline \multicolumn{3}{|c|}{ Organic Product Judgement } & 0.85 & 0.89 & 0.54 \\
\hline OPJ1 & $0.72 * * *$ & 0.52 & & & \\
\hline OPJ2 & $0.78^{* * *}$ & 0.61 & & & \\
\hline OPJ3 & $0.76^{* * *}$ & 0.58 & & & \\
\hline OPJ4 & $0.74^{* * *}$ & 0.55 & & & \\
\hline OPJ5 & $0.79 * * *$ & 0.62 & & & \\
\hline OPJ6 & $0.76^{* * *}$ & 0.58 & & & \\
\hline OPJ7 & $0.56^{* * *}$ & 0.31 & & & \\
\hline
\end{tabular}

To measure the internal consistency of scales, PLS produces two indicators: Cronbach's alpha $(\alpha)$ and composite reliability $\left(\rho_{c}\right)$. The latter is considered by some authors to be superior to the former because of its independence from the number of attributes associated with each construct [70]. 
The interpretation of both indices is similar, and values above 0.70 are considered reasonable $[67,71]$. The results obtained showed compliance with this requirement, ensuring minimized measurement error.

Convergent validity was examined using the average variance extracted (AVE) index, which quantifies the amount of variance that a construct captures from its indicators in relation to the amount of variance due to measurement error [69]. For all latent variables, AVE values were above the minimum benchmark of 0.50 , which means that at least $50 \%$ of the variance in the indicators is accounted for [70]. Likewise, to test discriminant validity, it was verified that the manifest variables correlated more strongly with their associated latent variable than with any other latent variable [67]. As Table 3 displays, the square roots of the AVE values (diagonal elements) were larger than the standardized correlations among constructs (off-diagonal elements), suggesting satisfactory discriminant validity [70].

Table 3. Correlations, square roots of average variance extracted (AVE), and summary statistics.

\begin{tabular}{lcccc}
\hline & $\mathbf{1}$ & $\mathbf{2}$ & $\mathbf{3}$ & $\mathbf{4}$ \\
\hline 1. Defense motivation & $(0.71)$ & & & \\
2. Accuracy motivation & $0.65^{* *}$ & $(0.72)$ & & \\
3. Claim credibility & $0.22^{* *}$ & $0.22^{* *}$ & $(0.77)$ & \\
4. Organic product judgement & $0.22^{* *}$ & $0.21^{* *}$ & $0.58^{* *}$ & $(0.73)$ \\
5. Knowledge & $-0.17^{* *}$ & $-0.26^{* *}$ & $-0.26^{* *}$ & $-0.21^{* *}$ \\
\hline Mean $(M)$ & 3.21 & 2.72 & 3.39 & 3.39 \\
Standard Deviation $(S D)$ & 0.75 & 0.78 & 0.80 & 0.81 \\
\hline Note: Square roots of AVE are in parentheses. ${ }^{* *} p<0.01$.
\end{tabular}

\subsection{Assessment of the Structural Model}

Once the reliability and validity of the measurement model were evaluated, the hypothesized relations among latent variables were analyzed. A bootstrapping procedure with 500 resamples was applied to determine the statistical significance of each estimated path in the model (Table 4).

Table 4. Structural model results.

\begin{tabular}{cc}
\hline Direct Effects & Path Coef. $(\boldsymbol{\beta})$ \\
\hline H1: Claim credibility $\rightarrow$ Organic product judgement & $0.58^{* * *}$ \\
H2: Knowledge $\rightarrow$ Claim credibility & $-0.22^{* * *}$ \\
H3a: Defense motivation $\rightarrow$ Claim credibility & $0.16^{*}$ \\
H3b: Defense motivation $x$ Knowledge $\rightarrow$ Claim credibility & -0.11 \\
H4a: Accuracy motivation $\rightarrow$ Claim credibility & 0.06 \\
H4b: Accuracy motivation $x$ Knowledge $\rightarrow$ Claim credibility & $0.12^{*}$ \\
\hline Indirect Effects & Path Coef. $(\beta)$ \\
\hline Knowledge $\rightarrow$ Claim credibility $\rightarrow$ Organic product judgement & $-0.13^{* * *}$ \\
Defense motivation $\rightarrow$ Claim credibility $\rightarrow$ Organic product judgement & $0.09^{*}$ \\
Defense motivation $x$ Knowledge $\rightarrow$ Claim credibility $\rightarrow$ Organic product judgment & -0.07 \\
Accuracy motivation $\rightarrow$ Claim credibility $\rightarrow$ Organic product judgement & 0.03 \\
Accuracy $x$ Knowledge $\rightarrow$ Claim credibility $\rightarrow$ Organic product judgement & $0.07^{*}$ \\
\hline Note: ns (non-significant); ${ }^{*} p<0.05 ; * * *<0.001$, based on $t(499)$, two-tailed test.
\end{tabular}

As expected, the positive effect of claim credibility on organic product judgement was statistically significant $(\beta=0.58, p<0.001)$, thus supporting H1. Likewise, in support of H2, knowledge had a negative direct effect on claim credibility $(\beta=-0.22, p<0.001)$ and a negative indirect effect on organic product judgement, so that participants who received basic training on organic certification and labelling reported lower levels of claim credibility than participants in the low-knowledge group $(M=3.17<M=3.59 ; t=5.55, p<0.001)$. 
In support of $\mathrm{H} 3 \mathrm{a}$, the positive effect of defense motivation on claim credibility was statistically significant $(\beta=0.16, p<0.05)$. However, H3b was rejected, because the interaction effect between defense motivation and knowledge on claim credibility was not statistically significant. The left chart in Figure 1 shows the relationship between defense motivation and credibility for low-and high-knowledge respondents.

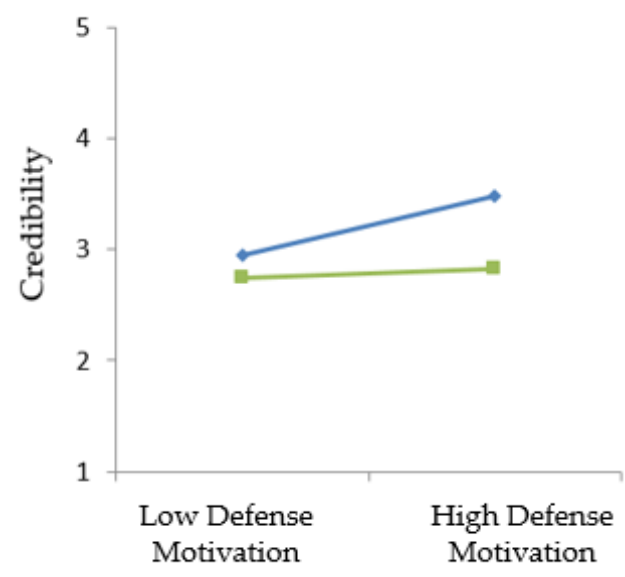

(a)

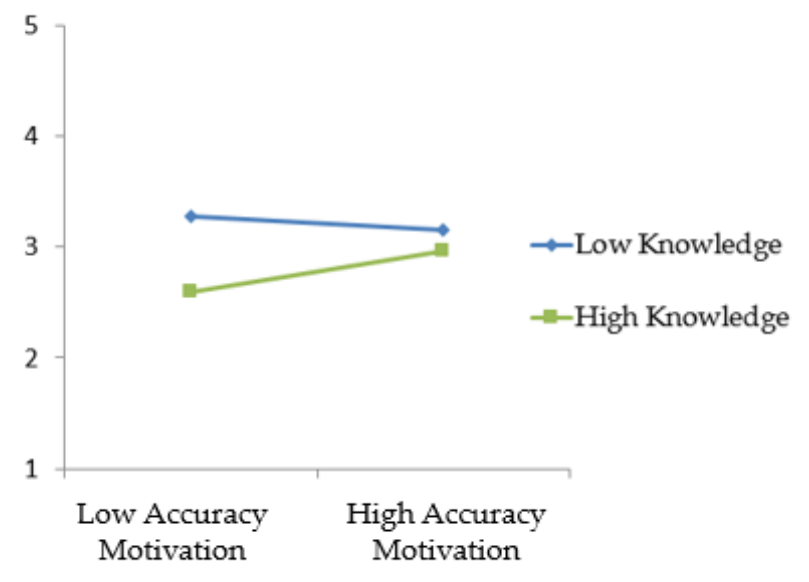

(b)

Figure 1. Interaction effects: (a) Interaction effect of defense motivation and knowledge on claim credibility; (b) interaction effect of accuracy motivation and knowledge on claim credibility.

The figure illustrates that, for high-knowledge participants, defense motivation had no effect on claim credibility, whereas, in the low-knowledge condition, credibility rose as defense motivation increased. Although according to PLS analyses these interaction effects were not statistically significant, it is worth noting that they pointed to the hypothesized direction.

The expected negative effect of accuracy motivation on claim credibility was not statistically significant, thus rejecting H4a. There was a statistically significant effect of the interaction between accuracy motivation and knowledge on credibility, but this effect was positive and not negative as expected $(\beta=0.12, p<0.05)$. Therefore, H4b was also rejected. The right chart in Figure 1 shows that, for low-knowledge participants, accuracy motivation scarcely had a negative effect on claim credibility, whereas, in the high-knowledge condition, credibility rose sharply as accuracy motivation increased.

Table 4 also includes the indirect effects of all exogenous variables in the model on organic product judgement, through the mediating role of claim credibility. Coherently with the results commented previously, claim credibility was found to mediate the negative effect of knowledge $(\beta=-0.13$, $p<0.001)$, the positive effect of defense motivation $(\beta=0.09, p<0.05)$, and the interactive positive effect of accuracy motivation and knowledge $(\beta=0.07, p<0.05)$ on organic product judgement [72].

Table 5 summarizes some basic indexes of global adjustment of the structural model. Although many experts agree that model fit criteria are in their early stage of research and are not often useful for PLS [63], the essential criterion seems to be the coefficient of determination $\left(R^{2}\right)$ obtained for each endogenous construct, which should be higher than 0.10 [73]. Both organic product judgement $\left(R^{2}=0.34\right)$ and claim credibility $\left(R^{2}=0.11\right)$ exceeded that minimum requirement, so that the model explained $34 \%$ of variance in organic product judgement. Moreover, the $Q^{2}$ values associated with the Stone-Geisser criterion $[74,75]$ were consistently higher than zero, indicating that prerequisites of predictive relevance for the model were fulfilled [69]. 
Table 5. Overall fit.

\begin{tabular}{cc}
\hline Index & Value \\
\hline$R^{2}$ Organic product judgement & 0.34 \\
$R^{2}$ Claim credibility & 0.11 \\
$Q^{2}$ Organic product judgement & 0.18 \\
$Q^{2}$ Claim credibility & 0.06 \\
SRMR & 0.06 \\
RMS_theta & 0.10 \\
GoF & 0.33
\end{tabular}

Note. SRMR = standardized root mean square residual; RMS = root mean squared; GoF $=$ goodness of fit.

Table 5 also reports the standardized root mean square residual (SRMR $=0.06$ ), which is defined as the difference between the observed correlation and the model implied correlation matrix and thus allows assessing the average magnitude of the discrepancies between observed and expected correlations as an absolute measure of fit criterion [76]. A value less than 0.08 is considered a good fit [77]. Likewise, the RMS_theta is the root mean squared residual covariance matrix of the outer model residuals [78], values below 0.12 indicating a well-fitting model [76], as in this case (RMS_theta $=0.10$ ). Finally, the global effect size measure for PLS path modelling developed by Tennenhaus et al. [79], goodness of fit, was obtained $(\mathrm{GoF}=0.33)$, which is defined as the geometric mean of the average communality and the average $R^{2}$ for the endogenous constructs. The value obtained indicated good performance of the structural model [80]. Figure 2 summarizes the research model.

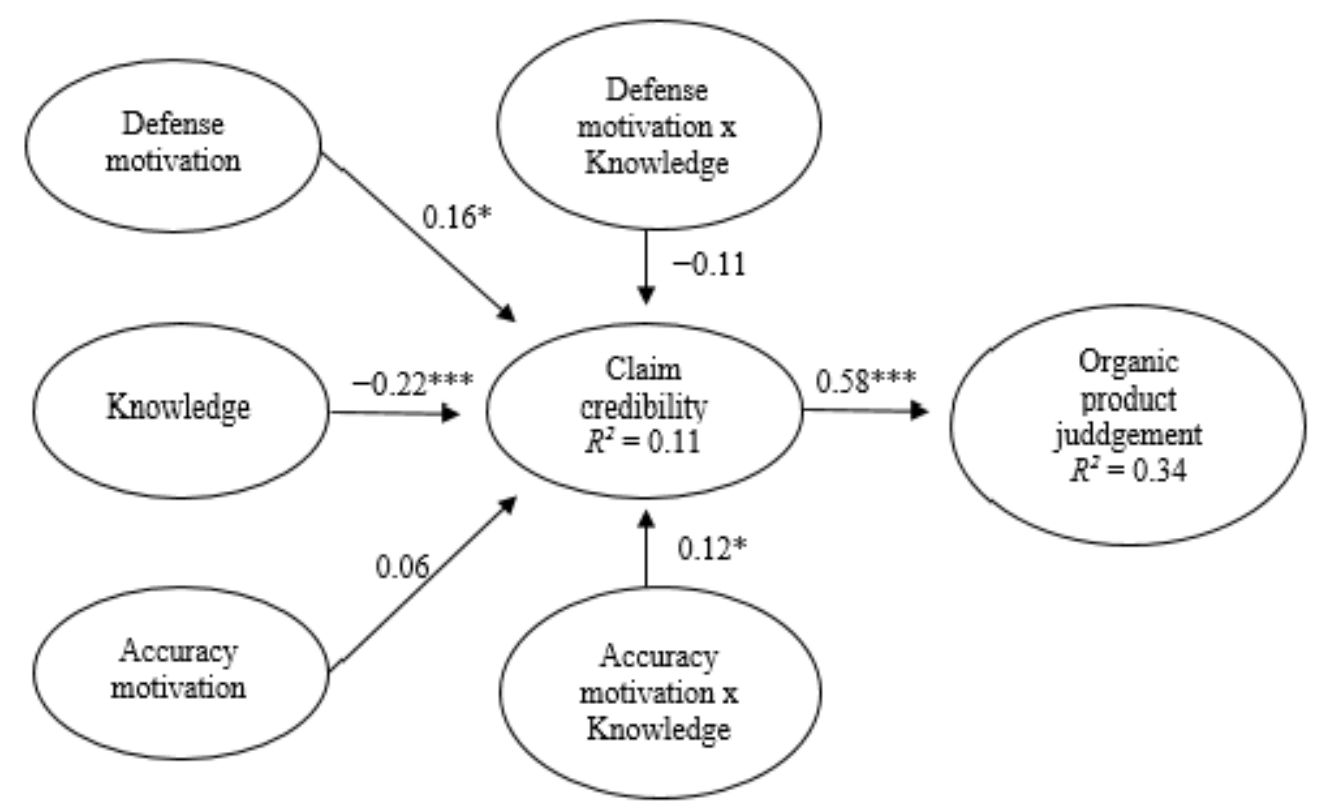

Figure 2. Research model. Note: ${ }^{*} p<0.05 ;{ }^{* * *} p<0.001$, based on $t(499)$, two-tailed test.

\section{Discussion}

In line with previous contributions in the literature, the results in this study show that the credibility granted by consumers to green advertising claims is directly related to the attribution of organic properties to products, then constituting a heuristic way of thinking that allows for making quick decisions with little cognitive effort, despite the fact that consumers do not have appropriate knowledge about their meaning $[5,46]$. Furthermore, when appropriate knowledge is not available, consumers seem to attribute credibility to organic claims to the extent that they appear as congruent with their personal goals and allow the reinforcement of self-image $[5,20,39]$. This unfounded trust places consumers in a position of vulnerability to possible greenwashing actions and misleading advertising by companies, as they do not have cognitive capacity enough to question the most visible 
commercial information and to evaluate relevant product attributes [3,12,45]. In short, wanting to do good does not necessarily imply knowing how to do it well, which questions the effectiveness of many purchasing behaviors of consumers with little knowledge to critically analyze the organic character of products.

In addition, it was found that providing consumers with basic information on certification and eco-labelling allowed them to significantly increase their knowledge about, then reduce the credibility attributed to the commercial claim used for research purposes in the study, as well as the judgements on the organic nature of the product associated with it. This result is in line with the idea that consumers more sensitized and trained to consume organic food products show greater skepticism about the reliability of green claims and are more prepared to scrutinize package information and are more protected from the risks of superficial heuristic thought $[3,10,48]$.

Complementarily, an interesting finding from the research indicates that increasing the consumers' level of knowledge modifies the way in which the perceived credibility of claims is built, based on the underlying motivational factors, although the results in this regard were different as expected. On the one hand, it is concluded that increasing consumers' knowledge does not allow to significantly attenuate the relationship between defense motivation and claim credibility, although the graphic representation of the interactive effects allows intuiting a certain trend in this sense, which must be investigated further in future research. On the other hand, it was found that generating knowledge in consumers reduces, rather than increases, the gap between actual and desired confidence, thus positively affecting the credibility of the commercial badge and the resulting judgement. According to the HSM, such gap reduction reinforces the tendency to use heuristic thinking and not to seek additional information as expected $[26,28,38]$.

The explanation of these intriguing findings could be linked to the two-week time lag between the training given to the individuals within the high-knowledge condition and the measurement of the variables of claim credibility and organic product judgement. If training had a significant impact, maybe participants had time enough to experiment with the knowledge acquired, seeking for official symbols and labels in real-world purchase situations. In this sense, we should remember that once consumers use deliberate thinking in their initial choices of green products, processing is likely to become automatic after several experiences $[3,34,35]$. Thus, in the second stage of the study, participants might have acquired the ability to effectively and correctly use the claim 'organic' as a heuristic cue, knowing that this term can only be used in advertising officially certified products. This interpretation also allows us to explain the positive effect of defense motivation on credibility, since it is certain that the judgements issued are consistent with personal goals and self-image reinforcement.

The conclusions derived from this study have some practical implications; first of all, for public authorities dedicated to the design of policies to promote ecological production and consumption. In this sense, in addition to promoting the identification of green products obtained in accordance with current regulations, it is necessary to improve the regulation and control of the ambiguous and opportunistic advertising that, despite not reporting on the organic nature of the product, tries to be credible for the consumers and fit into their self-image, then leading them to form erroneous judgements and to make biased purchase decisions [5,17]. Likewise, the findings of the study may be useful for entities and professionals committed to protecting consumer rights and fighting greenwashing. In this sense, it should be noted that, in addition to contributing to the development of more restrictive policies with misleading advertising, it seems necessary to work for the empowerment of consumers and the prevention of biased purchase decisions through specific educational campaigns to help them differentiate between official hallmarks of those which are not, then reducing the credibility of the latter and motivating individuals to employ a more rational thought in searching and correctly interpreting and considering the necessary information that, once generalized, will allow them to make quick and effective decisions $[3,4,34,35]$.

In line with the above stated, this research can help those responsible for marketing in food companies dedicated to organic production when designing promotional campaigns to assist consumers 
in order to quickly and accurately assess the green benefits of the products concerned. Thus, a suggestion could be the inclusion in advertising campaigns of short educational claims that contribute to the identification of official labels on packaging and the understanding of their precise meaning, encouraging consumers to look for such symbols in their usual purchase experiences [17]. This way, reliable heuristic cues will be generated allowing the consumer a justification on the superiority of the product [3]. These types of advertising claims can have such positive collateral effects as, for example, reducing the reluctance of those consumers who are more skeptical and less likely to buy sustainable products due to their inability to completely understand the meaning of environment-related label claims [22], or simply by improving consumer awareness of general sustainability issues, even when they do not use eco-labels as a decisive purchasing criterion [48].

This study suffers from limitations that could be addressed in future research. First, it should be noted that, despite the fact that the research has made it possible to reach some important conclusions in the context of the hypotheses laid, and the fit indexes of the research model have been adequate, the percentage of variance explained in the claim credibility by the variables related to knowledge, defense motivation, and accuracy motivation have been quite limited, while some results concerning the relationship between both types of motivations and claim credibility have been opposite to what was expected. Although it has been argued that a possible explanation for these results can be found in the time lapse between the two research phases in the experimental condition of high-knowledge, it was not possible to control the influence of certain strange variables during that period. Therefore, the interpretation of the obtained results should be contrasted in future studies carrying out a more controlled analysis of the immediate effects of the increase in knowledge about certification and eco-labelling in the generation of systematic thinking in consumers, as well as their evolution towards effective heuristic thinking after seeking, several times, interpretation of official evidence. In such longitudinal studies, considering other potential antecedents of claim credibility in the context of the HSM or other dual models seems likewise necessary, thus allowing a more precise knowledge of how the processing of green symbols works and how it can be used to improve consumers' skills in their purchase decisions.

Together with the above, the research has been focused on the study of the determinants of the making of organic product judgements in the evaluation of the attributes of the product prior to the purchase decision, so that it is not possible to quantify the effects of the variables of the model on the real purchase of organic products. In this sense, although it seems demonstrated that providing information can be effective in giving consumers the initial knowledge they need to engage in more deliberate forms of sustainable behavior change [81,82], meta-analytic reviews suggest that interventions providing information have a significant albeit modest influence on pro-environmental actions and are often not enough to spur long-term sustainable changes $[83,84]$. Therefore, it seems necessary to analyze, in future studies, to what extent the reduction in credibility and the increase in motivation for seeking additional information, as the verified effects of increasing consumers' knowledge in this research, have capacity to generate acts of purchasing organic products, possibly in interaction with other dimensions such as the evaluation of the quality and the price of the product.

In this sense, it should be also noted that this study has focused on a single commercial claim related to a well-known Spanish banana brand, so it is possible that its credibility was nurtured by the own confidence in the main brand. New studies could compare the results obtained for the commercial claim in the context of its combination with brands of different notoriety or congruence with respect to their ecological commitment, identifying other possible factors associated to the claim credibility and organic product judgement. Testing the model with other categories of processed organic food or other products of sporadic purchase and greater involvement would also be pertinent, as they would allow, by definition, a more systematic analysis of the information in the evaluation of the attributes of the product [3]. In addition, it seems interesting to test the research model with ambiguous and fraudulent commercial claims, in order to determine in a more precise way how credibility is built under such circumstances and to what extent the increase in the consumers' cognitive capacity in 
terms of knowledge has a protective effect to avoid the use of such claims as heuristic cues in making purchase decisions.

Finally, the study has focused on a specific sample of young university students, as it was considered a consumer profile adjusted to the research objectives, given the greater responsiveness of young people to sustainability issues [49,53-55]. The generalization of the results to other groups of customers is therefore compromised, then making it necessary to replicate the research with other samples of greater sociodemographic variability.

Author Contributions: Conceptualization, A.L. and J.-L.V.; methodology, A.L. and C.S.-P.; software, A.L.; validation, A.L. and C.S.-P.; formal analysis, A.L.; investigation, A.L. and C.S.-P.; data curation, A.L.; writing-original draft preparation, A.L. and J.-L.V.; writing—review and editing, A.L. and J.-L.V.; visualization, A.L.; supervision, A.L. and J.-L.V. All authors have read and agreed to the published version of the manuscript.

Funding: This research received no external funding.

Conflicts of Interest: The authors declare no conflict of interest.

\section{Appendix A. Questionnaire}

\section{Appendix A.1. Defense Motivation}

Please, assess to what extent you feel identified with the following statements related to the consideration of ecological criteria in your purchase of fresh fruits and vegetables (use a scale ranging from $1=$ not identified at all to $5=$ completely identified):

DM1-When I buy products with an organic distinctive or mention, I feel that I am contributing to the well-being of society

DM2-Purchasing products from organic farming is a small gesture to contribute to respect for the environment

DM3-I like to consider myself as a consumer concerned about the impacts of his/her purchases on the environment

DM4-When I see that a product is distinguished by its organic nature, I feel that purchasing it is the right thing to do

DM5-As far as possible, I try to contribute something to my environment through the products I buy

DM6-Purchasing organic farming products makes me feel good about myself

DM7-Whenever it is in my hand, I try to contribute to environmental causes through my purchase decisions concerning certain products

\section{Appendix A.2. Accuracy Motivation}

Please, assess to what extent you feel identified with the following statements related to the consideration of ecological criteria in your purchase of fresh fruits and vegetables (use a scale ranging from $1=$ not identified at all to $5=$ completely identified):

AM1-I usually make sure that the products I buy have been obtained without the use of chemical pesticides

AM2-I avoid purchasing products that contain artificial substances (additives, preservatives, etc.)

AM3 - I tend to look for evidence that the products I buy have been obtained with cultivation methods that preserve and protect the environment

AM4-For me it is fundamental that the products I buy are identified with some official organic certification

AM5-I like to have guarantees that the products I consume have been obtained without the use of chemical fertilizers

AM6-I usually look for evidence that the products I consume have been obtained respecting the natural growth rate of the plant 
AM7-I like to know that the products I choose have been obtained with cultivation methods adapted to the optimal use of local conditions

AM8-I try to avoid purchasing products containing genetically modified organisms

\section{Appendix A.3. Claim Credibility}

When assessing the organic nature of the banana identified by the following claim, to what extent you consider the claim to be (use a scale ranging from $1=$ nothing at all to $5=$ completely)

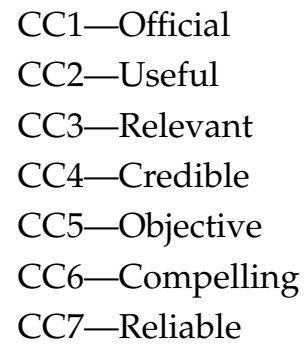

\section{Appendix A.4. Organic Product Judgement}

Please, indicate to what extent you associate the following claim with a banana (use a scale ranging from $1=$ nothing at all to $5=$ completely)

OPJ1-Obtained without the use of chemical pesticides

OPJ2-Obtained without artificial additives

OPJ3-Produced in an environmentally friendly way

OPJ4-Obtained respecting the natural growth rate of the plant

OPJ5-Obtained without the use of chemical fertilizers

OPJ6-Not genetically modified

OPJ7-Obtained with cultivation methods adapted to the optimal use of local conditions

\section{References}

1. Alevizou, P.J.; Oates, C.J.; McDonald, S. The weel(s) of knowledge: The decoding of sustainability claims in the UK and in Greece. Sustainability 2015, 7, 8729-8747. [CrossRef]

2. Darnall, N.; Ji, H.; Vázquez-Brust, D.A. Third-party certification, sponsorship and consumers' ecolabel use. J. Bus. Ethics 2018, 150, 953-969. [CrossRef]

3. Stanton, J.V.; Cook, L.A. Product knowledge and information processing of organic foods. J. Consum. Mark. 2019, 36, 240-252. [CrossRef]

4. Hoek, J.; Roling, N.; Holdsworth, D. Ethical claims and labelling: An analysis of consumers' beliefs and choice behaviours. J. Mark. Manag. 2013, 29, 772-792. [CrossRef]

5. Maniatis, P. Investigating factors influencing consumer decision-making while choosing green products. J. Clean. Prod. 2016, 132, 215-218. [CrossRef]

6. The European Parliament and the Council of the European Union. Regulation (EU) 2018/848 of the European Parliament and of the Council of 30 May 2018 on organic production and labelling of organic products and repealing Council Regulation (EC) No 834/2007. Off. J. Eur. Union 2018, L150, 1-92.

7. Auger, P.; Devinney, T. Do what consumers say matter? The misalignment of preferences with unconstrained ethical intentions. J. Bus. Ethics 2007, 76, 361-383. [CrossRef]

8. Park, C.W.; Iyer, E.S.; Smith, D.C. The effect of situational factors on in-store grocery shopping behavior: The Role of store environment and time available for shopping. J. Consum. Res. 1989, 15, 422-433. [CrossRef]

9. Payne, J.W.; Bettman, J.R.; Johnson, E.J. The Adaptive Decision Maker; Cambridge University Press: New York, NY, USA, 1993.

10. Lee, W.J.; Shimizu, M.; Kniffin, K.M.; Wansink, B. You taste what you see: Do organic labels bias taste perceptions? Food Qual. Prefer. 2013, 29, 33-39. [CrossRef] 
11. Magnier, L.; Schoormans, J. Consumer reactions to sustainable packaging: The interplay of visual appearance, verbal claim and environmental convern. J. Environ. Psychol. 2015, 44, 53-62. [CrossRef]

12. Sörqvist, P.; Haga, A.; Langeborg, L.; Holmgren, M.; Wallinder, M.; Nöstl, A.; Seager, P.B.; Marsh, J.E. The green halo: Mechanisms and limits of the eco-label effect. Food Qual. Prefer. 2015, 43, 1-9. [CrossRef]

13. Perrini, F.; Castaldo, S.; Misani, N.; Tencati, A. The impact of corporate social responsibility associations on trust in organic products marketed by mainstream retailers: A study of Italian consumers. Bus. Strategy Environ. 2010, 19, 512-526. [CrossRef]

14. Sirieix, L.; Delanchy, M.; Remaud, H.; Zepeda, L.; Gurviez, P. Consumers' perceptions of individual and combined sustainable food labels: A UK pilot investigation. Int. J. Consum. Stud. 2013, 37, 143-151. [CrossRef]

15. Schleenbecker, R.; Hamm, U. Information needs for a purchase of Fairtrade coffee. Sustainability 2015, 7, 5944-5962. [CrossRef]

16. Taufique, K.M.R.; Siwar, C.; Talib, B.; Sarah, F.H.; Chamhuri, N. Synthesis of constructs for modelling consumers' understanding and perception of eco-labels. Sustainability 2014, 6, 2176-2200. [CrossRef]

17. Prothero, A.; Peattie, K.; McDonagh, P. Communicating green strategies: A study of on-pack communication. Bus. Strategy Environ. 1997, 6, 74-82. [CrossRef]

18. Skubisz, C. Naturally good: Front-of-package claims as message cues. Appetite 2017, 108, 506-511. [CrossRef]

19. Gifford, K.; Bernard, J. The effect of information on consumers' willingness to pay for natural and organic chicken. Int. J. Consum. Stud. 2011, 35, 282-289. [CrossRef]

20. Hahnel, U.J.J.; Arnold, O.; Waschto, M.; Korkaj, L.; Hillmann, K.; Roser, D.; Spada, H. The power of putting a label on it: Green labels weigh heavier than contradicting product information for consumers' purchase decisions and post-purchase behavior. Front. Psychol. 2015, 6, 1-17. [CrossRef]

21. Grunert, K.G. Current issued in the understanding of consumer food choices. Trends Food Sci. Technol. 2002, 13, 275-285. [CrossRef]

22. Samant, S.S.; Seo, H.S. Effects of label understanding level on consumers' visual attention toward sustainability and process-related label claims found on chicken meat products. Food Qual. Prefer. 2016, 50, 48-56. [CrossRef]

23. Chaiken, S. Heuristic versus systematic information processing and the use of source versus message cues in persuasion. J. Personal. Soc. Psychol. 1980, 39, 752-766. [CrossRef]

24. Chaiken, S. The heuristic model of persuasion. In Social Influence: The Ontario Symposium; Zanna, M.P., Olson, J.M., Herman, C.P., Eds.; Erlbaum: Hillsdale, NJ, USA, 1987; Volume 5, pp. 3-39.

25. Chaiken, S.; Liberman, A.; Eagly, A.H. Heuristic and systematic processing within and beyond the persuasion context. In Unintended Thought; Uleman, J.S., Bargh, J.A., Eds.; Guilford Press: New York, NY, USA, 1989; pp. 212-252.

26. Zuckerman, A.; Chaiken, S. A heuristic-systematic processing analysis of the effectiveness of product warning labels. Psychol. Mark. 1998, 15, 621-642. [CrossRef]

27. Bradu, C.; Orquin, J.L.; Thøgersen, J. The mediated influence of a traceability label on consumer's willingness to buy the labelled product. J. Bus. Ethics 2013, 124, 283-295. [CrossRef]

28. Chaiken, S.; Ledgerwood, A. A theory of heuristic and systematic information processing. In Handbook of Theories of Social Psychology; Lange, P.A.M.V., Kruglanski, A.W., Higgins, E.T., Eds.; SAGE Inc.: New Delhi, India, 2011; Volume 1, pp. 246-266.

29. Chen, S.; Chaiken, S. The heuristic-systematic model in its broader context. In Dual Process Theories in Social Psychology; Chaiken, S., Trope, Y., Eds.; Guilford Press: New York, NY, USA, 1999; pp. 73-96.

30. Gigerenzer, G.; Gaissmaier, W. Heuristic decision making. Annu. Rev. Psychol. 2011, 62, 451-482. [CrossRef]

31. Kahneman, D. Maps of bounded rationality: A perspective on intuitive judgment and choice. In Les Prix Nobel: The Nobel Prizes 2002; Frangsmyr, T., Ed.; Nobel Found: Stockholm, Sweden, 2003; pp. 449-489.

32. Shah, A.K.; Oppenheimer, D.M. Heuristics made easy: An effort-reduction framework. Psychol. Bull. 2008, 137, 207-222. [CrossRef]

33. Hayat, K.; Jianjun, Z.; Zammer, H.; Iqbal, S. Understanding the influence of corporate social responsibility practices on impulsive buying. Corp. Soc. Responsib. Environ. Manag. 2020, 27, 1454-1464. [CrossRef]

34. Thøgersen, J.; Jorgensen, A.; Sandager, S. Consumer decision-making regarding a "green" everyday product. Psychol. Mark. 2012, 29, 187-197. [CrossRef]

35. Thøgersen, J.; Haugaard, P.; Olsen, A. Understanding consumer responses to ecolabels. Eur. J. Mark. 2010, 44, 1787-1810. [CrossRef] 
36. Ratneshwar, S.; Chaiken, S. Comprehension's role in persuasion: The case of its moderating effect on the persuasive impact of source cues. J. Consum. Res. 1991, 18, 52-62. [CrossRef]

37. Wood, W.; Rhodes, N.; Biek, M. Working knowledge and attitude strength: An information processing analysis. In Attitude Strength: Antecedents and Consequences; Petty, R.E., Krosnick, J.A., Eds.; Lawrence Erlbaum Associates: Mahwah, NJ, USA, 1995; pp. 283-313.

38. Bohner, G.; Moskowitz, G.B.; Chaiken, S. The interplay of heuristic and systematic processing of social information. Eur. Rev. Soc. Psychol. 1995, 6, 33-68. [CrossRef]

39. Chaiken, S.; Giner-Sorolla, R.; Chen, S. Beyond accuracy: Defence and impression motives in heuristic and systematic information processing. In The Psychology of Action: Linking Motivation and Cognition to Behavior; Gollwitzer, P.M., Bargh, J.A., Eds.; Guilford: New York, NY, USA, 1996; pp. 553-578.

40. Ayyub, S.; Wang, X.; Asif, M.; Ayyub, R.M. Antecedents of trust in organic foods: The mediating role of food related personality traits. Sustainability 2018, 10, 3597. [CrossRef]

41. Gutiérrez, A.; Thornton, T.F. Can consumers understand sustainability through seafood eco-labels? A U.S. and UK case study. Sustainability 2014, 6, 8195-8217. [CrossRef]

42. Nuttavuthisit, K.; Thøgersen, J. The importance of consumer trust for the emergence of a market for green products: The case of organic food. J. Bus. Ethics 2017, 140, 323-337. [CrossRef]

43. Janssen, M.; Hamm, U. The mandatory EU logo for organic food: Consumer perceptions. Br. Food J. 2012, 114, 335-352. [CrossRef]

44. Penz, E.; Hofmann, E.; Hartl, B. Fostering sustainable travel behavior: Role of sustainability labels and goal-directed berhavior regarding touristic services. Sustainability 2017, 9, 1056. [CrossRef]

45. Thøgersen, J. Psychological determinants of paying attention to eco-labels in purchase decisions: Model development and multinational validation. J. Consum. Policy 2000, 23, 285-313. [CrossRef]

46. Galarraga Gallastegui, I. The Use of Eco-Labels: A Review of the Literature. Eur. Environ. 2002, 12, 316-331. [CrossRef]

47. Grunert, K.G.; Hieke, S.; Wills, J. Sustainability labels on food products: Consumer motivation, understanding and use. Food Policy 2014, 44, 177-189. [CrossRef]

48. de Boer, J. Sustainability labelling schemes: The logic of their claims and their functions for stakeholders. Bus. Strategy Environ. 2003, 12, 254-264. [CrossRef]

49. Kim, H.J.; Lee, S.H.; Yang, K. The heuristic-systemic model of sustainability stewardship: Facilitating sustainability values, beliefs and practices with corporates social responsibility drives and eco-labels/indices. Int. J. Consum. Stud. 2015, 39, 249-260. [CrossRef]

50. Bianchi, C.; Reyes, V.; Devenin, V. Consumer motivations to purchase from benefit corporations (B Corps). Corp. Soc. Responsib. Environ. Manag. 2020, 27, 1445-1453. [CrossRef]

51. Hahnel, U.J.J.; Gölz, S.; Spada, H. How does green suit me? Consumers mentally match perceived product attributes with their domain-specific motives when making green purchase decisions. J. Consum. Behav. 2014, 13, 317-327. [CrossRef]

52. Park, C.W.; Lessig, V.P. Familiarity and its impact on consumer decision biases and heuristics. J. Consum. Res. 1981, 8, 223-230. [CrossRef]

53. Bedard, S.A.N.; Tolmie, C.R. Millennials' Green consumption behaviour: Exploring the role of social media. Corp. Soc. Responsib. Environ. Manag. 2018, 25, 1388-1396. [CrossRef]

54. Sciarelli, M.; Tani, M.; Landi, G.; Turriziani, L. CSR perception and financial performance: Evidences from Italian and UK asset management companies. Corp. Soc. Responsib. Environ. Manag. 2020, 27, 841-851. [CrossRef]

55. The Nielsen Company. The Sustainability Imperative. 2015. Available online: https://www.nielsen.com/ssa/ en/insights/report/2015/the-sustainability-imperative-2/ (accessed on 22 September 2020).

56. Ministry of Agriculture, Fisheries and Food. Informe del Consumo Alimentario en España 2019 [Report on Food Consumption in Spain]; Ministry of Agriculture, Fisheries and Food: Madrid, Spain, 2019.

57. AEOC Shopeperview. El Shopper Millennial de Frutas y Hortalizas [The Millennial Shopper of Fruits and Vegetables]; AECOC: Barcelona, Spain, 2017.

58. Association of Organizations of Banana Producers of the Canary Islands. Estadísticas 2019 de Producción y Comercialización de Plátano de Canarias [Statistics 2019 of Production and Marketing of Banana from the Canary Islands]; ASPROCAN: Santa Cruz de Tenerife, Spain, 2020. 
59. Association of Organizations of Banana Producers of the Canary Islands. Estudio de las Diferencias entre el Plátano de Canarias y la Banana [Study of the Differences between the Canarian Banana and the Banana]; ASPROCAN: Santa Cruz de Tenerife, Spain, 2013.

60. Canarian Institute of Agrofood Quality. Datos Estadísticos de Agricultura Ecológica en Canarias [Statistical Data on Organic Agriculture in the Canary Islands]. 2019. Available online: https://www.gobiernodecanarias.org/ agp/icca/temas_calidad/agricultura_ecologica/estadisticas/ (accessed on 22 September 2020).

61. Hinkin, T.R. A review of scale development practices in the study of organizations. J. Manag. 1995, 21, 967-988. [CrossRef]

62. Podsakoff, P.M.; MacKenzie, S.B.; Lee, J.-Y.; Podsakoff, N.P. Common method biases in behavioural research: A critical review of the literature and recommended remedies. J. Appl. Psychol. 2003, 88, 879-902. [CrossRef]

63. Hair, J.F.; Hult, G.T.M.; Ringle, C.M.; Sarstedt, M.A. Primer on Partial Least Squares Structural Equation Modeling (PLS-SEM), 2nd ed.; Sage: Thousand Oaks, CA, USA, 2017.

64. Chin, W.W.; Marcolin, B.L.; Newsted, P.R. A partial least squares latent variable modeling approach for measuring interaction effects: Results from a Monte Carlo simulation study and an electronic mail emotion/adoption study. Inf. Syst. Res. 2003, 14, 189-217. [CrossRef]

65. Fornell, C.; Bookstein, F.L. A comparative analysis of two structural equation models: Lisrel and PLS applied to market data. In A Second Generation of Multivariate Analysis; Fornell, C., Ed.; Praeger: New York, NY, USA, 1982; Volume 1, pp. 289-324.

66. Wold, H. Systems analysis by partial least squares. In Measuring the Unmeasurable; Nijkamp, P., Leitner, H., Wrigley, N., Eds.; Martinus Nijhoff Publishers: Dordrecht, The Netherlands, 1985; pp. 221-251.

67. Barclay, D.; Higgins, C.; Thompson, R. The partial least squares (PLS) approach to causal modelling: Personal computer adoption and use as an illustration. Technol. Stud. 1995, 2, 285-309.

68. Hulland, J. Use of partial least squares (PLS) in strategic management research: A review of four recent studies. Strateg. Manag. J. 1999, 20, 195-204. [CrossRef]

69. Chin, W.W. Issues and opinion on structural equation modelling. MIS Q. 1998, 22, 7-16.

70. Fornell, C.; Larcker, D.F. Evaluating structural equation models with unobservable variables and measurement error. J. Mark. Res. 1981, 18, 39-50. [CrossRef]

71. Nunnally, J.C.; Bernstein, I.H. Psychometric Theory, 3rd ed.; McGraw-Hill: New York, NY, USA, 1994.

72. Zhao, X.; Lynch, J.G.; Chen, Q. Reconsidering Baron and Kenny: Myths and Truths about Mediation Analysis. J. Consum. Res. 2010, 37, 197-206. [CrossRef]

73. Falk, R.F.; Miller, N.B. A Primer for Soft Modeling; The University of Akron Press: Akron, OH, USA, 1992.

74. Geisser, S. A predictive approach to the random effects model. Biometrica 1974, 61, 101-107. [CrossRef]

75. Stone, M. Cross-validatory choice and assessment of statistical predictions. J. R. Stat. Soc. 1974, 36, 111-133. [CrossRef]

76. Henseler, J.; Dijkstra, T.K.; Sarstedt, M.; Ringle, C.M.; Diamantopoulos, A.; Straub, D.W.; Ketchen, D.J.; Hair, J.F.; Hult, G.T.M.; Calantone, R.J. Common Beliefs and Reality about Partial Least Squares: Comments on Rönkkö \& Evermann (2013). Organ. Res. Methods 2014, 17, 182-209.

77. Hu, L.T.; Bentler, P.M. Fit indices in covariance structure modeling: Sensitivity to underparameterized model misspecification. Psychol. Methods 1998, 3, 424-453. [CrossRef]

78. Lohmöller, J.B. Latent Variable Path Modeling with Partial Least Squares; Physica-Verlag: Heidelberg, Germany, 1989.

79. Tennenhaus, M.; Vinzi, V.E.; Chatelin, Y.M.; Lauro, C. PLS path modeling. Comput. Stat. Data Anal. 2005, 48, 159-205. [CrossRef]

80. Wetzels, M.; Odcerkerken-Schroder, G.; Van Oppen, C. Using PLS path modelling for assessing hierarchical construct models: Guidelines and empirical illustration. MIS Q. 2009, 33, 177-195. [CrossRef]

81. Gifford, R.; Nilsson, A. Personal and social factors that influence pro-environmental concern and behaviour: A review. Int. J. Psychol. 2014, 49, 141-157. [CrossRef] [PubMed]

82. White, K.; Habib, R.; Hardisty, D.J. How to SHIFT consumer behaviors to be more sustainable: A literature review and guiding framework. J. Mark. 2019, 83, 22-49. [CrossRef]

83. Delmas, M.A.; Fischlein, F.; Asensio, O.I. Information strategies and energy conservation behavior: A meta-analysis of experimental studies from 1975 to 2012. Energy Policy 2013, 61, 729-739. [CrossRef] 
84. Osbaldiston, R.; Schott, J.P. Environmental sustainability and behavioral science: Meta-analysis of proenvironmental behavior experiments. Environ. Behav. 2012, 44, 257-299. [CrossRef]

Publisher's Note: MDPI stays neutral with regard to jurisdictional claims in published maps and institutional affiliations.

(C) 2020 by the authors. Licensee MDPI, Basel, Switzerland. This article is an open access article distributed under the terms and conditions of the Creative Commons Attribution (CC BY) license (http://creativecommons.org/licenses/by/4.0/). 